\title{
Dynamic 3D (4D) in objective classification of severe back deformities
}

\section{H Diers*, S Mooshake and KR Heitmann}

\author{
Address: Diers International, Dillenbergweg 4, 65388 Schlangenbad, Germany \\ Email: H Diers* - diers@diers.de \\ * Corresponding author
}

\author{
from 6th International Conference on Conservative Management of Spinal Deformities \\ Lyon, France. 21-23 May 2009 \\ Published: I4 December 2009 \\ Scoliosis 2009, 4(Suppl 2):OI6 doi:I0.II86/I748-7|6I-4-S2-OI6
}

This abstract is available from: http://www.scoliosisjournal.com/content/4/S2/OI6

(c) 2009 Diers et al; licensee BioMed Central Ltd.

\section{Objectives}

To perform a non-invasive dynamic analysis of movement ranges, asymmetries in scoliosis, and other back deformities and to average a series of images.

\section{Background}

Objective parameters in diagnostics and treatment of back problems are normally acquired through invasive, timeconsuming and/or expensive methods. Non-invasive and significantly objective parameters can be extracted from a dynamic 4D reconstruction.

\section{Methods}

The Formetric 4D measurement system dynamically scans and reconstructs human back surfaces with a frequency of up to $24 \mathrm{~Hz}$. Automatically detectable fixed points and invariant features on the surface correlates to a high degree of accuracy with the spinal processes and pelvis. Thus, it is possible to calculate parameters derived from spine and pelvic position, displacement and rotation, things such as kyphotic and lordotic angles, pelvic symmetry and torsion, spinal rotation and displacement. Variations in postural movements in upright position of patients may, however, lead to significant reduction of repeatability of examinations. A series of images taken with automatic calculation of the average values will solve this problem. In a dynamic examination, predefined movements are analyzed regarding symmetry and range of motion.

\section{Results}

The robustness and reproducibility of reconstruction parameters significantly improves by taking the average of a series of images recorded over a period of 3-10 sec. In the Matthias's test, kyphotic and lordotic angles show the break-up of the standing posture over time. The Romberg test gives information about fluctuation movements of the upper body relative to the pelvis. Asymmetry by stepping gives information about pelvic and spinal blockages.

\section{Conclusion}

Significant objective dynamic parameters can be calculated without invasive methods or the use of ionizing radiation. 